medRxiv preprint doi: https://doi.org/10.1101/2021.08.05.21261627; this version posted August 7, 2021. The copyright holder for this preprint (which was not certified by peer review) is the author/funder, who has granted medRxiv a license to display the preprint in It is made available under a CC-BY-NC-ND 4.0 International license .

\title{
Systematic review protocol exploring the impact of the COVID-19 pandemic on the wellbeing of general practitioners
}

Jefferson, L., Golder, S., Dale, V., Essex, H., McHugh, E. Bloor, K.

Department of Health Sciences, University of York, Heslington, YO10 5DD

Correspondence to: L Jefferson laura.jefferson@york.ac.uk Area 4 Seebohm Rowntree Building, Department of Health Sciences, University of York, Heslington, YO10 5DD.

Word count: 1609 
medRxiv preprint doi: https://doi.org/10.1101/2021.08.05.21261627; this version posted August 7, 2021. The copyright holder for this

preprint (which was not certified by peer review) is the author/funder, who has granted medRxiv a license to display the preprint in It is made available under a CC-BY-NC-ND 4.0 International license .

\section{Abstract}

\section{Background}

Over recent years chronic stress and burnout have been reported by doctors working in general practice in the UK NHS and internationally. The COVID-19 pandemic has changed general practitioners' working lives - adding potential pressures from avoiding infection and addressing pent-up demand for care, but also changing processes such as rapidly taking up remote consultations. To date, there has been a focus on exploring the impact of the pandemic on the wellbeing of hospital clinicians. No registered systematic reviews currently focus on exploring the impact of the pandemic on the mental health and wellbeing of general practitioners.

\section{Aims and objectives}

To synthesise the current international evidence base exploring the impact of COVID-19 on the mental health and wellbeing of general practitioners, and which factors are associated with their reported mental health and wellbeing during the pandemic.

\section{Methods}

In this paper we report a systematic review protocol, following PRISMA guidance. In our search strategy we will identify primary research studies or systematic reviews exploring the mental health and wellbeing of general practitioners during the COVID-19 pandemic in four databases (MEDLINE, Embase, PsychInfo and Medrxiv) and Google Scholar. We will hand-search reference lists and grey literature.

Two reviewers will undertake all stages including study selection, data extraction and quality assessment, with arbitration by a third reviewer where necessary. We will use standardised quality assessment tools to ensure transparency and reduce bias in quality assessment. Depending on the quality of included studies, we may undertake a sensitivity analysis by excluding studies from narrative synthesis that are rated as low quality using the checklists.

We will describe the findings across studies using narrative thematic data synthesis, and if sufficiently homogenous data are identified, we will pool quantitative findings through metaanalysis.

Keywords: General practitioners, Wellbeing, well-being, Mental health, burnout, stress, COVID-19, coronavirus 
medRxiv preprint doi: https://doi.org/10.1101/2021.08.05.21261627; this version posted August 7, 2021. The copyright holder for this

preprint (which was not certified by peer review) is the author/funder, who has granted medRxiv a license to display the preprint in

It is made available under a CC-BY-NC-ND 4.0 International license .

\section{Introduction}

Prior to the COVID-19 pandemic, chronic stress and burnout threatened the mental health of doctors working in general practice, the quality of patient care ${ }^{1}$ and the sustainability of the health care system. ${ }^{2}$ General practitioners (GPs) play a crucial role as 'gatekeepers' to the health service, and yet greater quantity and complexity of work have led to high levels of reported job stress, lower satisfaction, burnout and intentions to leave medicine. , $^{3,4,5}$

Internationally, medical workforce wellbeing has been described as a "public health crisis." 7,8 In the UK, prior to the pandemic, $80 \%$ of doctors reported characteristics associated with very high risk of burnout, ${ }^{9}$ with those in general practice and emergency medicine at highest risk. ${ }^{10,11}$

There are clear added risks to the wellbeing of the medical workforce during COVID-19, and during the recovery period, as we emerge from the pandemic with a large backlog of unmet patient needs for non-COVID-19 care. Research from earlier epidemics indicates the potential for considerable increased stress and burnout in health professionals. ${ }^{12}$ Sources of stress for GPs include rapid change, risks of infection, remote working and reductions in face-to-face patient care. There may also, however, be some changes that could improve GPs' wellbeing, including public gratitude, financial investment, e-consultations and improved cooperation; factors previously shown to positively affect workforce morale and wellbeing.

Internationally, research evidence tends to focus on the impact of the COVID-19 pandemic on frontline hospital workers, perhaps due to their roles in treating the illness and potential greater exposure to infection. A systematic review of international evidence is needed to explore the potential impact of COVID-19 on the mental health and wellbeing of doctors working in general practice, so that future health policy and workplace interventions can be tailored to suit these specific experiences.

\section{Aims}

In this systematic review we aim to synthesise current international evidence on the impact of COVID-19 on the mental health and wellbeing of general practitioners. In addition, and if data allows, we will explore factors which are associated with the mental health and wellbeing of general practitioners during the COVID-19 pandemic.

\section{Methods}

An initial scoping exercise, searching PROSPERO-registered studies and contacting study authors to avoid duplication in this rapidly expanding research field, revealed no existing reviews with a focus on general practitioner mental health and wellbeing during the COVID-19 pandemic.

To ensure the transparency of reporting for this systematic review we will use the Preferred Reporting Items for Systematic Reviews and Meta-Analyses (PRISMA) guidance. ${ }^{13}$ Our eligibility criteria will capture studies with GPs as the population of interest, which measure mental health and wellbeing outcomes during the COVID-19 pandemic. 
medRxiv preprint doi: https://doi.org/10.1101/2021.08.05.21261627; this version posted August 7, 2021. The copyright holder for this

preprint (which was not certified by peer review) is the author/funder, who has granted medRxiv a license to display the preprint in It is made available under a CC-BY-NC-ND 4.0 International license .

\section{Criteria for including studies}

Population: General practitioners. We will exclude studies of doctors not working in primary care. We will exclude studies of a variety of health professionals, including GPs, if they do not provide subgroup analyses or data specifically for the GP group.

Intervention / type of exposure: the impact of the COVID-19 pandemic.

Comparator: This is not an interventional systematic review; therefore, no comparator will be used. Studies may explore trends over time.

Outcome measures: Measures of psychological wellbeing, stress and burnout, and as secondary outcomes, the impact on factors including absenteeism and workforce retention.

Study Design: Studies will not be limited by design, but we will include only empirical primary research and systematic reviews. Editorials and case reports will be excluded.

\section{Search methods for identification of studies}

We will develop a search strategy with input from a multi-disciplinary research team, including subject matter experts, an experienced information specialist and through consultation with GP and patient stakeholders. We will search the following databases; MEDLINE, Embase, PsychInfo and, owing to the large body of COVID-19 literature being published in this space, Medrxiv and Google Scholar will also be searched. We will search from 2020 onwards and limit to the English language, using search terms for general practitioner and relating to general practice, including consideration of international terminology, for example the inclusion of terms relating to 'family practice.' Search terms will focus on COVID-19, as well as date restrictions to only include studies published during 2020 and 2021. We will hand search reference lists and grey literature. We will update searches prior to publication to ensure inclusion of all literature in this rapidly expanding field.

\section{Study selection}

We will download all records to Endnote, removing any duplicated studies. Two reviewers will independently screen studies for inclusion.

In the first stage of screening, we will classify all titles and abstracts as eligible, excluded or uncertain about eligibility. Each reviewer will be blind to the other's assessment. The full texts for all eligible or potentially eligible papers will then be retrieved and reviewed. A third reviewer will resolve any disagreements regarding inclusion of studies.

We will record excluded articles, with the reasons for exclusion, to generate a flow diagram as recommended by the PRISMA statement. ${ }^{14}$

Data extraction

A data extraction form will be designed and piloted including information regarding study design, sample size, sample characteristics, primary and secondary outcomes. One reviewer will perform data extraction, with a $20 \%$ sample second checked by a second reviewer. 
medRxiv preprint doi: https://doi.org/10.1101/2021.08.05.21261627; this version posted August 7, 2021. The copyright holder for this

preprint (which was not certified by peer review) is the author/funder, who has granted medRxiv a license to display the preprint in It is made available under a CC-BY-NC-ND 4.0 International license .

\section{Assessment of methodological quality}

We will assess the quality of identified studies using standardised checklists, chosen according to the study design. We will use the AMSTAR checklist ${ }^{15}$ for reviews, the CASP quality checklist ${ }^{16}$ for observational and qualitative studies, and the Joanna Briggs Institute checklist for Analytical Crosssectional Studies. ${ }^{17}$ Depending on the quality of included studies, we may undertake a sensitivity analysis by excluding studies from narrative synthesis that are rated as low quality using the checklists. Two reviewers will independently conduct quality appraisal, with disagreements resolved by a third reviewer.

\section{Synthesis of findings}

Our data synthesis will be narrative, using a thematic approach to describe the findings across studies, with subgroup analyses according to study type. Where appropriate (i.e. sufficiently homogenous data and study type), studies with quantitative findings will be pooled using metaanalysis. We will analyse subgroups of study types. Where sufficient data is available, we will analyse different subgroups of key GP characteristics (such as career stage, gender, ethnicity).

\section{Protocol amendments}

Where changes are required to this protocol, the details will be outlined in the published final review and updated in PROSPERO. However, no further amendments to this protocol are foreseen.

\section{Discussion}

Internationally, general practitioners report increasing stress and burnout, with clear potential additional pressures likely during the COVID-19 pandemic and recovery period. There are currently no systematic reviews of general practitioners' wellbeing during the COVID-19 pandemic. Given the complexity and quantity of workload stressors placed on general practitioners prior to and during the pandemic, this review is timely in order to highlight how best to support the future working lives of GPs. In this study we aim to synthesise this international evidence base to explore the impact of COVID-19 on the mental health and wellbeing of general practitioners, which will inform future workforce policy as we move out of the pandemic. We anticipate this work will also inform future research, including the potential to design and implement workplace interventions to support the wellbeing of general practice teams. We will disseminate findings from this systematic review through peer-reviewed journals and presentations to national audiences including policymakers and the Royal College of General Practitioners. 
medRxiv preprint doi: https://doi.org/10.1101/2021.08.05.21261627; this version posted August 7, 2021. The copyright holder for this preprint (which was not certified by peer review) is the author/funder, who has granted medRxiv a license to display the preprint in It is made available under a CC-BY-NC-ND 4.0 International license .

\section{Author contributions}

This study was designed and conceived by $\amalg$ and KB, with methodological expertise input from SG. $L$ wrote the first draft of this manuscript, to which all authors commented. All authors have read and agreed the final version.

\section{Funding}

This report is independent research commissioned and funded by the Department of Health and Social Care Policy Research Programme (Exploring the impact of COVID-19 on GPs' wellbeing, NIHR202329). The views expressed in this publication are those of the author(s) and not necessarily those of the Department of Health and Social Care.

Competing interests

None declared 
medRxiv preprint doi: https://doi.org/10.1101/2021.08.05.21261627; this version posted August 7, 2021. The copyright holder for this preprint (which was not certified by peer review) is the author/funder, who has granted medRxiv a license to display the preprint in It is made available under a CC-BY-NC-ND 4.0 International license .

\title{
References
}

\begin{abstract}
${ }^{1}$ Panagioti M, Geraghty K, Johnson J, et al. Association Between Physician Burnout and Patient Safety, Professionalism, and Patient Satisfaction: A Systematic Review and Meta-analysis. JAMA Intern Med. 2018;178(10):1317-1331. doi:10.1001/jamainternmed.2018.3713

${ }^{2}$ King's Fund (2019) Introduction to Closing the Gap Report: Available:

https://www.kingsfund.org.uk/publications/closing-gap-health-care-workforce [last accessed 14 April 21)
\end{abstract}

${ }^{3}$ Gibson, J., Sutton, M., Spooner, S., Checkland, K. (2018). Ninth National GP Worklife Survey. University of Manchester: Policy Research Unit in Commissioning and the Healthcare System Manchester Centre for Health Economics

${ }^{5}$ Kane, L (2019) Medscape National Physician Burnout, Depression and suicide report 2019. Medscape, 2019. Available: https://www.medscape. com/slideshow/2019-lifestyle-burnoutdepression-6011056\#2 [Accessed 01 July 2020]

${ }^{6}$ Shanafelt TD, Boone S, Tan L, et al. Burnout and satisfaction with work-life balance among US physicians relative to the general US population. Arch Intern Med. 2012;172(18):1377-1385. doi:10.1001/archinternmed.2012.3199

${ }^{7}$ Lancet, The (2019a) Physician burnout: a global crisis: Editorial. The Lancet: 394 (10193, p93

${ }^{8}$ Lancet, The (2019b) Physician burnout: the need to re-humanise health systems: Editorial. The Lancet. 394 (10209) P1591

${ }^{9}$ British Medical Association (BMA) (2019) Caring for the mental health of the medical workforce; $B M A$, London

${ }^{10}$ General Medical Council (GMC) (2019) The state of medical education and practice in the UK. GMC, 2019. Available: https://www.gmc-uk.org/about/what-we-do-and-why/data-andresearch/the-state-of-medical-education-and-practice-in-the-uk [Accessed 02 July 2020]

${ }^{11}$ McKinley N, McCain RS, Convie L, et al (2020) Resilience, burnout and coping mechanisms in UK doctors: a cross-sectional study BMJ Open 2020;10: e031765. doi: 10.1136/bmjopen-2019-031765

${ }^{12}$ Maunder, R. G., Lancee, W. J., Balderson, K. E., Bennett, J. P., Borgundvaag, B., Evans, S., Fernandes, C. M., Goldbloom, D. S., Gupta, M., Hunter, J. J., McGillis Hall, L., Nagle, L. M., Pain, C., Peczeniuk, S. S., Raymond, G., Read, N., Rourke, S. B., Steinberg, R. J., Stewart, T. E., VanDeVeldeCoke, S., Wasylenki, D. A. (2006). Long-term psychological and occupational effects of providing hospital healthcare during SARS outbreak. Emerging infectious diseases, 12(12), 1924-1932. https://doi.org/10.3201/eid1212.060584

13 Moher D, Liberati A, Tetzlaff J, Altman DG, The PRISMA Group (2009). Preferred Reporting Items for Systematic Reviews and Meta-Analyses: The PRISMA Statement. BMJ 2009;339:b2535, doi: 10.1136/bmj.b2535

${ }^{14}$ Moher D, Liberati A, Tetzlaff J, Altman DG, The PRISMA Group (2009). Preferred Reporting Items for Systematic Reviews and Meta-Analyses: The PRISMA Statement. BMJ 2009;339:b2535, doi: 10.1136/bmj.b2535 
medRxiv preprint doi: https://doi.org/10.1101/2021.08.05.21261627; this version posted August 7, 2021. The copyright holder for this preprint (which was not certified by peer review) is the author/funder, who has granted medRxiv a license to display the preprint in It is made available under a CC-BY-NC-ND 4.0 International license .

${ }^{15}$ Shea BJ, Reeves BC, Wells G, Thuku M, Hamel C, Moran J, Moher D, Tugwell P, Welch V, Kristjansson E, Henry DA. AMSTAR 2: a critical appraisal tool for systematic reviews that include randomised or non-randomised studies of healthcare interventions, or both. BMJ. 2017 Sep 21;358:j4008.

${ }^{16}$ Critical Appraisal Skills Programme (2018). CASP Qualitative Checklist. [online] Available at: https://casp-uk.net/wp-content/uploads/2018/01/CASP-Qualitative-Checklist-2018.pdf (last accessed: 20/02/21)

${ }^{17}$ Joanna Briggs Institute (2017) Checklist for Analytical Cross Sectional Studies [online] Available at: https://joannabriggs.org/sites/default/files/2019-05/JBI Critical Appraisal-

Checklist for Analytical Cross Sectional Studies2017 0.pdf (last accessed 16/12/20) 